\title{
MOBILE BANKING E INTERATIVIDADE: UMA ANÁLISE COMPARATIVA DOS APLICATIVOS BANCO DO BRASIL E CAIXA ECONÔMICA FEDERAL ${ }^{1}$
}

\author{
MOBILE BANKING AND INTERACTIVITY: A COMPARATIVE ANALYSIS OF \\ BANCO DO BRASIL APPLICATIONS AND CAIXA ECONÔMICA FEDERAL
}

\author{
Pabla Pereira da Silva ${ }^{2}$ e Taís Steffenello Ghisleni ${ }^{3}$
}

\section{RESUMO}

Considerando o fato que o número de usuários de smartphones aumenta a cada ano e que o telefone móvel está mais moderno com o uso da tecnologia dos aplicativos que promovem interações sociais e ajudam a realizar tarefas cotidianas, o artigo buscou entender de que modo ocorre as interações entre banco e cliente através dos aplicativos do Banco do Brasil e Caixa Econômica Federal. Conceitos sobre interatividade, usabilidade, midiatização, banco móvel e comportamento do consumidor de tecnologia foram utilizados, a fim de trazer base teórica para o estudo. A metodologia de natureza qualitativa fez uso de observação e análise de conteúdo dos App's citados. Como resultado, o artigo conclui que o aplicativo do Banco do Brasil está mais midiatizado do que o aplicativo da Caixa e, dessa forma, parece interagir melhor com os clientes, buscando promover uma relação que distancia o tempo e espaço enquanto reorganiza tarefas diárias dos usuários.

Palavras-chave: Midiatização; comportamento do consumidor; tecnologia; interatividade, aplicativos.

\section{ABSTRACT}

Considering the fact that the number of smartphone users increases each year and that the mobile phone is more modern with the use of application technology that promotes social interactions and helps to perform daily tasks, the article sought to understand how interactions occur between bank and customer through the applications of Banco do Brasil and Caixa Economica Federal. Concepts on interactivity, usability, mediatization, mobile banking and technology consumer behavior were used in order to bring theoretical basis for the study. The qualitative methodology made use of observation and content analysis of the mentioned Apps. As a result, the article concludes that the Banco do Brasil application is more mediatized than the Caixa application and thus appears to interact better with customers, seeking to foster a relationship that distances time and space while reorganizing;

Keywords: Mediatization; consumer behavior; technology; interactivity, applications.

\footnotetext{
${ }^{1}$ Artigo resultante do curso de Especialização MBA em Marketing da Universidade Franciscana - UFN.

${ }^{2}$ Jornalista. Mestre em Administração (UFSM). MBA em Marketing (UFN). E-mail: pablapereira@yahoo.com.br

${ }^{3}$ Doutora. Professora do Curso de Publicidade e Propaganda e do Mestrado em Humanidades e Linguagens da Universidade Franciscana - UFN. E-mail: taisghisleni@yahoo.com.br
} 


\section{INTRODUÇÃO}

O número de usuários de smartphones aumenta a cada ano, seja para bater papo, conectar-se às redes sociais, trabalhar ou procurar diversão, o fato é que essa tecnologia ocupa um espaço significativo na vida de muitas pessoas. De acordo com o site IAB Brasil e o relatório da pesquisa Brasil Conectado - Hábitos de consumo de mídia - 2014, a compra de smartphones continua a aumentar e, desde 2014 tornou-se o principal dispositivo eletrônico pessoal dos brasileiros. (IAB BRASIL, 2013).

A pesquisa aponta que a posse de iPads e tablets também aumentou, mais de 1/3 da população brasileira possui um dispositivo desta categoria. A principal atividade realizada nos smartphones são relacionadas a interações sociais, seguida de músicas e notícias. Além disso, metade dos donos de smartphones está aberta à ideia de usar o celular como forma de pagamento em vez de utilizar cartão de crédito ou débito. (IAB BRASIL, 2013).

Hoje, com o aumento da tecnologia, existem à disposição das pessoas, várias maneiras para solucionar problemas simples do cotidiano, e muitas delas se realizam por meios de aplicativos móveis, ou seja, sistemas desenvolvidos para serem instalados em nossos dispositivos, especialmente nos smartphones ou tablets. Fernandes (2016, online) explica que "Os aplicativos são normalmente conhecidos como "apps" ou "app mobile". A sigla "app" é uma abreviatura de "aplicação de software". [...] Os aplicativos são instalados nos dispositivos móveis através de uma loja online, como Google Play, AppStore ou Windows Phone Store". Alguns aplicativos podem estar disponíveis de forma gratuita ou através de mensalidades ou valores fixos que devem ser pagos para o seu uso.

Os aplicativos móveis têm o propósito de auxiliar o dia a dia das pessoas e justamente por causa desses é possível acessar a conta corrente e fazer transações bancárias sem precisar ir até o banco ou a um caixa eletrônico, apenas utilizando a internet. Falando especificamente sobre o banco móvel (mobile banking), os usuários dessa tecnologia podem acessar seus serviços de cartão de crédito, realizar transferências entre contas correntes, pagamentos de boletos, ter acesso a poupança, financiamentos e outros, através do aplicativo disponível (de forma gratuita) pelo banco na loja online do smartphone. Os apps podem ser acessados diariamente por usuários do mundo inteiro que buscam entretenimento, informação e outros conteúdos que possam facilitar o seu dia a dia (FEIJÓ; GONÇALVEZ; GOMEZ, 2013).

Apps ou aplicativos são softwares, cujo objetivo é ajudar o usuário a realizar determinadas tarefas que podem estar relacionadas a entretenimento, trabalho ou funções do dia a dia. (LUCCA, 2013). Uma pesquisa da Conecta, plataforma web do Ibope Inteligência revelou que a grande maioria dos internautas brasileiros utilizam pelo menos um aplicativo de banco no seu smartphone.

Acessar a conta corrente e realizar transações a qualquer hora em qualquer lugar é uma das facilidades de se utilizar o aplicativo do seu banco. De acordo com os resultados do CONECTAí Express, pesquisa nacional online e multiclientes do CONECTA, revela que 
$79 \%$ dos internautas brasileiros utilizam pelo menos um app de banco, sendo que os aplicativos da Caixa e do Banco do Brasil são os mais utilizados. (CONECTAí EXPRESS, 2017, online).

O aplicativo do Banco do Brasil (BB), por exemplo, já permite abrir uma conta apenas informando o CPF. E, seguindo essa tendência, a Caixa Econômica Federal (Caixa) investe em tecnologia para trazer melhorias a seu aplicativo. Uma pesquisa realizada pela Conecta, o aplicativo da Caixa apareceu como o mais usado, tendo sido citado por $26 \%$ dos entrevistados, seguido de perto pelo Banco do Brasil, com 23\%. Outros apps mencionados representam o Itaú, com 20\%, Bradesco, com 19\%, e Santander, com 11\%. No entanto, como qualquer outro aplicativo, os App's. do Banco do Brasil e da Caixa recebem atualizações e são modificados (de tempos em tempos) com o intuito de facilitar ainda mais o seu acesso e funcionalidades, além das questões de segurança. Pois, a cada nova versão pode-se encontrar novidades e mais uma (ou mais de uma) transação bancária aceita pelo app.

Por meio de pesquisa exploratória no site e nas redes sociais dos bancos citados, é possível notar que boa parte das divulgações feitas são para incentivar o uso dos aplicativos. O BB faz uso da \#maisquedigital em várias de suas postagens nas redes sociais, essas postagens explicam as funcionalidades e vantagens da tecnologia mobile banking. Da mesma forma, a Caixa também faz divulgações de incentivo para o uso dos seus App's.

Sendo assim, a partir da realidade apresentada, as instituições bancárias estão se adaptando ao contexto tecnológico e investindo em aplicativos que ampliam suas formas de interação com os consumidores. Conforme Terra (2008), a comunicação digital alterou significativamente o modo como as organizações se comunicam e se relacionam com os seus públicos de interesse. Mais virtual do que física, essa interação pode otimizar alguns serviços, deixando-os mais fáceis e rápidos, como no caso dos aplicativos de banco. Segundo Feijó, Gonçalvez e Gomez (2013), a maioria dos smartphones, hoje, possuem funcionalidades avançadas que são potencializadas pelos apps, pelo acesso à internet e pela capacidade de armazenar dados em seus sistemas operacionais. Tais características proporcionam experiências diferenciadas aos usuários.

Ramos, Pimenta e Rodrigues (2010) ressaltam que o setor bancário pode ser destacado como um dos que mais investe em tecnologias de informação. Clientes que utilizam os meios digitais apresentam-se como mais rentáveis as instituições bancárias (PIRES; DA COSTA FILHO, 2008). Diante das observações prévias expostas, forma-se a questão que o artigo busca investigar: Quais as funcionalidades presentes nos aplicativos do Banco do Brasil e da Caixa que se destacam por ampliar a interação entre cliente e agência?

Para tanto, estabelecemos o objetivo geral de estudar de que modo ocorre as interações entre banco e cliente através dos aplicativos do Banco do Brasil e Caixa. E os objetivos específicos serão: descrever as funcionalidades presentes nos aplicativos do Banco do Brasil e Caixa; observar as possibilidades de interação oferecidas pelos aplicativos de cada banco investigado, aos clientes; investigar 
dados de pesquisas que apontem o crescimento de consumidores que utilizam os aplicativos; e, comparar as funcionalidades disponibilizadas para avaliar qual está mais midiatizado.

Considerando-se a constante evolução da tecnologia, bem como as mudanças no comportamento das pessoas no decorrer dos tempos, torna-se relevante o estudo em relação à influência das inovações tecnológicas, em especial dos aplicativos móveis, nas atividades diárias das pessoas e das organizações que oferecem esse tipo de tecnologia, que é o caso das instituições financeiras, através do serviço de mobile banking (MANI, CHOUK, 2017; GROHMANN et al. 2015). Pesquisas deste cunho tem grande importância e despertam interesse no meio acadêmico, tendo um crescimento no número de publicações (GROHMANN et al. 2015).

O uso das tecnologias está cada vez mais presente e necessário na execução das atividades diárias, vindo a facilitar de maneira significativa a realização das mesmas. Uma tecnologia que vem se destacando, com aumento progressivo de seu uso, são os aplicativos móveis (GROHMANN et al. 2015).

Portanto, sabendo da importância de se conhecer mais sobre as novas tecnologias e a maneira como elas afetam a vida das pessoas, surgiu a intenção de estudar de que modo essas tecnologias estão ampliando as interações entre o banco e o cliente através dos aplicativos móveis. A escolha do objeto de pesquisa são os aplicativos do Banco do Brasil e Caixa Econômica Federal, justificada através da pesquisa do CONECTAi Express, esses App's são os mobile banking mais usados pelos internautas brasileiros.

Sabemos que os aplicativos estão modificando a nossa forma de comunicação, de interação social, de entretenimento e, até mesmo, na maneira como executamos nossas tarefas diárias, mas somente através de estudos no campo é que podemos ter uma ideia sobre como os aplicativos estão interferindo na relação entre consumidor e empresa.

\section{MIDIATIZAÇÃO, TECNOLOGIA, INTERATIVIDADE E USABILIDADE}

O ambiente virtual e a comunicação propiciada pelas telecomunicações e pela Internet trouxeram novas características às organizações e diferentes formas de relacionamento com os clientes (BOTTENTUIT JR., 2008). Hoje, vivemos a era da comunicação interativa mediada através de aparelhos como smartphones, tablets e notebooks. O Banco do Brasil expõe essa questão através de propagandas que incentivam a segurança e a facilidade de se comunicar com o banco através do aplicativo. "Quer um jeito fácil e seguro de ir ao Banco do Brasil? Vai no APP! Baixe e use" (BANCO DO BRASIL, 2017).

Hjarvard (2014) explica que as mídias são usadas para uma pluralidade de finalidades, incluindo possibilitar a distanciação do espaço-tempo da modernidade e para aliviar os atores sociais das muitas tarefas de coordenação. O telefone móvel, por exemplo, parece suportar uma ampla "microcoordenação" do trabalho e da vida familiar (LING, 2004). 
A midiatização não se refere somente ao domínio da formação da opinião pública, várias formas de mídias estão integradas nas práticas da vida cotidiana. Conforme Hjarvard (2014), as mídias são coprodutoras de nossas representações mentais, de nossas ações e relacionamentos com outras pessoas em uma variedade de contextos privados. A comunicação de massa tem sido acrescentada através das mídias interativas, o que permite a todos não apenas receber, mas também participar de forma ativa em diversos modos de comunicação global.

A midiatização diz respeito às transformações estruturais de longa duração na relação entre a mídia e outras esferas sociais. Em contraste à mediação, que lida com o uso da mídia para práticas comunicativas específicas em interação situada, a midiatização preocupa-se com os padrões em transformação de interações sociais e relações entre os vários atores sociais, incluindo os indivíduos e as organizações (HJARVARD 2014).

Diante das novas formas de comunicação e interação no ambiente virtual, vamos abordar os conceitos de interatividade que se referem à interação entre o indivíduo e as tecnologias digitais. As primeiras pesquisas sobre interatividade em novos médias (MCMILLAN, 2002) focavam-se nas propriedades e características dos meios e das mensagens, definindo interatividade como uma característica da tecnologia que permitia uma comunicação multidirecional, suas diferentes funcionalidades permitiam ao usuário uma maior participação e controle nas atividades desencadeadas.

Matos (2005) explica que, diferente dessa abordagem, outras áreas de estudo (MCMILLAN, 2002) identificam a interatividade como sendo, pelo menos em parte, uma característica da percepção do sistema por parte do utilizador, isto é, a interatividade não é uma propriedade exclusiva da tecnologia, mas depende igualmente de quem utiliza tal tecnologia.

Sicília, Ruiz e Munuera (2005) falam que a interatividade representa a facilidade com que indivíduos e organizações se comunicam diretamente uns com os outros, sem restrições de distância ou tempo. Robb, McCarthy e Sheridan (1997) definem a interatividade como uma variação de combinações de conteúdo e comunicação criando um encontro com o consumidor. Ainda Coyle e Thorson (2001) e Sohn e Lee (2005) indicam três características inerentes à internet: (a) controle, (b) receptividade, (c) personalização.

A partir desses conceitos podemos entender a tecnologia como uma influenciadora no comportamento do indivíduo, sendo este o centro para a criação de novas médias e da própria interatividade. Conforme Matos (2005), os principais aspectos a considerar na avaliação da interatividade não são as soluções tecnológicas encontradas e suas propriedades, mas o modo como utilizadores percepcionam e utilizam essas soluções.

Outro aspecto importante e totalmente ligada a interatividade é a usabilidade. Os estudos em relação à usabilidade ganharam força a partir da década de 1990 e a preocupação com a usabilidade ganhou espaço em laboratórios de design em empresas como a Apple (FEIJÓ, GONÇALVEZ E GOMEZ, 2013). Segundo Brade (2002), a explosão de popularidade e da utilização dos computadores 
pessoais levantou a questão da usabilidade dos sistemas, da sua facilidade de aprendizagem e uso. Feijó, Gonçalvez e Gomez (2013) também explicam que a eficiência e a facilidade de uso são consideradas metas de usabilidade, ou seja, a usabilidade será fator decisivo para assegurar que os usuários não tenham dificuldades ao usar os sistemas e que essa utilização seja eficiente e agradável.

Assim, a interatividade passou a englobar fatores como a complexidade da escolha do utilizador, o esforço que este aplica, a prontidão de resposta do sistema, a sua monitorização, a facilidade de adição de novos dados, a facilidade de comunicação interpessoal (MCMILLAN, 2002). E dessa forma, ao criar um sistema interativo se fez imprescindível entender a necessidade dos usuários, tal sistema precisa ser objetivo e proporcionar qualidade na realização da tarefa desejada.

Fundamentando-se nas teorias da HCI - Homem, Computador e Interacção - os três elementos que compõem a sua área de aplicação podem ser traduzidos da seguinte maneira:

[....] No axioma máximo de compreender o utilizador, o seu contexto de utilização e as suas funções, compreender o sistema computacional que irá permitir o alcançar desses objetivos, e traduzir adequadamente todos esses elementos no design das interfaces e dos modelos de execução. (MATOS 2005).

Além disso, quando compreendido o processo da HCI, seu resultado deverá passar no teste dos três tipos de "usável" de Dix (2004): useful, permite realizar o que é suposto, usable, fazendo-o de forma fácil e natural, e used, criando no utilizador uma vontade de usar o sistema para fazer a tarefa. Com o avanço tecnológico e as novas tecnologias (tablets, smartphones e computadores) foram criadas ferramentas que ajudam o utilizador a realizar determinadas tarefas com sucesso. Sobre essa perspectiva, os bancos também se modernizam e criaram as plataformas E-Banking e Mobile Banking para serem usadas pelos clientes, essas plataformas realizam as tarefas através de objetivos que o sistema entenda e suporte. No próximo capítulo, vamos abordar sobre o E-Banking e o Mobile Banking.

\section{TECNOLOGIA E PLATAFORMAS E-BANKING E MOBILE BANKING}

Vivemos um tempo de constante revolução tecnológica e tal acontecimento pode impactar o dia a dia e o comportamento dos consumidores. A velocidade das tecnologias digitais ou tecnologias de informação e comunicação pode ser vista como um dos fatores determinantes para a criação de uma cultura contemporânea marcada, dentre outros aspectos, por novas formas de comunicação e, por consequência, sujeita a transformações em curso, ainda não apreendidas plenamente (PEREIRA, 2006).

Na mesma linha de pensamento, Laudon e Laudon (1999), informam que "a tecnologia é o meio pelo qual os dados são transformados e organizados para uso das pessoas. " A internet é um exemplo disso, fazemos uso dessa ferramenta para a comunicação, interação e, também, consumo. De acordo com Abbade e Noro (2012), este ambiente virtual tem capacidade única de melhorar a 
comunicação entre as organizações e consumidores, permitindo às organizações aprender sobre as suas necessidades, reduzir custos e melhorar a conveniência.

Sendo assim, muitas empresas estão fazendo uso de novas tecnologias para comunicar-se e interagir com os clientes, é o caso do atendimento bancário através da internet. O E-Banking (banco online) permite ao cliente realizar transferências, investimentos e pagamentos de contas somente com o uso da internet. Esse ambiente virtual proporciona um atendimento diferenciado ao cliente sendo considerado como o centro do E-Banking (ABBADE E NORO, 2012).

Essa nova forma de realizar transações bancárias reduz custos de operação e pode gerar um aumento de valor a ser entregue aos clientes. Turban (2000), explica que o uso do E-Banking reinventa a forma de operação das organizações, proporcionando ganhos significativos de produtividade, reinventando processos, reduzindo os custos operacionais e eliminando funções que não agregam valor.

Ao fazer uso da internet os bancos reduzem os custos por meio do comércio eletrônico. Conforme Abbade e Noro (2012), a redução de custos é importante para os bancos, pois estes estão sendo pressionados pela redução das margens de lucro, provocada tanto pelo aumento da concorrência, quanto pela crescente influência da tecnologia nos produtos e serviços bancários.

Outra plataforma que está crescendo e transformando o modo de acessar os serviços bancários é o Mobile Banking (conteúdo do banco por meio de um aparelho eletrônico móvel). Os bancos estão investindo em aplicativos que tornam possível o acesso a conta corrente e a efetuar transações bancárias através do smartphone.

Segundo Strutzel (2015), o crescimento intenso e acelerado dos dispositivos móveis provocou mudanças profundas na sociedade, desde os hábitos e comportamentos das pessoas, até alterações nos meios de comunicação, entretenimento, relacionamentos e compras. Com o avanço da tecnologia, os celulares tornaram-se objetos cada vez mais inseparáveis de seus donos, tendo em vista que os aparelhos dispõem de entretenimento e funcionalidades para quase tudo.

\section{COMPORTAMENTO DO CONSUMIDOR COM RELAÇÃO À TECNOLOGIA}

Conforme Nielsen (2016), a dependência dos dispositivos móveis está crescendo no mundo. 5 em cada 10 consumidores globais dizem que não imaginam sua vida sem seu smartphone. No Brasil, a mesma proporção reconhece essa dependência, ficando acima da média da América Latina (4 em cada 10).

A Pesquisa Nielsen sobre Pagamentos, Serviços Bancários e Compras via Celular foi realizada entre $1^{\circ}$ e 23 de março de 2016, e reuniu consumidores on-line em 63 países.

Com relação ao Brasil, 73\% dos respondentes dizem desfrutar da liberdade de estarem conectados em qualquer momento e lugar e consideram que os dispositivos móveis têm facilitado suas vidas, além disso, $71 \%$ reconhece que os dispositivos móveis têm sido facilitadores da crescente substituição das interações presenciais pelas eletrônicas. Para 51\% não se trata de um problema, já que preferem escrever mensagens de texto do que falar (NIELSEN 2016). 
A pesquisa também informa que apesar da grande disposição dos brasileiros em fazer uso do banco móvel, algumas barreiras como segurança em primeiro lugar (61\%), seguido pela preferência em realizar os serviços em uma agência física (44\%) e pela não necessidade de usar serviços bancários móveis (16\%) somam-se aos motivos que levam a não usar os aplicativos de banco.

Para Parasuraman e Colby (2001), uma vez que uma nova tecnologia é apresentada, os indivíduos compradores se comportam de múltiplas maneiras. Esses comportamentos dependem e variam, em grande parte, segundo suas crenças, valores e sentimentos. Em estudos de Parasuraman e Colby (2002), é possível encontrar a segmentação entre o perfil dos indivíduos com relação a tecnologia. Tal segmentação se divide em cinco grupos: os Exploradores; os Pioneiros; os Céticos; os Paranóicos e os Retardatários;

a) Exploradores: Neste grupo os indivíduos apresentam alto índice de prontidão para a tecnologia. São os primeiros a adotar uma nova tecnologia, pois possuem forte motivação e baixos fatores inibidores.

b) Pioneiros: Pode-se considerar o grupo dos pioneiros como aqueles fortemente motivados para a tecnologia, no entanto também podem apresentar, paralelamente, fortes fatores inibidores, ou seja, tem alto otimismo e inovatividade, mas também alto desconforto e insegurança com relação à tecnologia.

c) Céticos: Na mesma proporção que possuem pouca motivação para a tecnologia, esse grupo possui pouca inibição.

d) Paranoicos: Esse grupo de consumidores até acredita nos benefícios da tecnologia, entretanto, são inibidos por um alto grau de desconforto e insegurança.

e) Retardatários: Nessa categoria os indivíduos têm pouca motivação e alta inibição para a tecnologia.

Quadro 01 - Crenças diferentes dos segmentos de adoção de tecnologia.

\begin{tabular}{|l|l|l|l|l|}
\hline \multirow{2}{*}{} & \multicolumn{2}{|c|}{ Contribuintes } & \multicolumn{2}{c|}{ Inibidores } \\
\cline { 2 - 5 } & Otimismo & Caráter Inovador & \multicolumn{1}{c|}{ Desconforto } & Insegurança \\
\hline Exploradores & Alto & Alto & Baixo & Baixo \\
\hline Pioneiros & Alto & Alto & Alto & Alto \\
\hline Céticos & Baixo & Baixo & Baixo & Baixo \\
\hline Paranóicos & Alto & Baixo & Alto & Alto \\
\hline Retardatários & Baixo & Baixo & Alto & Alto \\
\hline
\end{tabular}

Fonte: Adaptado de Parasuraman e Colby (2002).

Nesse sentido, segundo Schiffman e Kanuk (2000), as atitudes refletem uma predisposição do consumidor a se comportar de maneira afirmativa ou de renúncia a respeito de um objeto. Em linha similar, Kretch et. al (1962) define atitude como uma predisposição para se comportar de uma forma consistente em relação a uma determinada classe de objetos. 
Ainda segundo Parasuraman e Colby (2002), essa vasta diferenciação dos consumidores de tecnologias é vista como uma tarefa complicada para a área de marketing, visto que assegurar a satisfação desses mais diversos públicos corresponde em ações únicas direcionadas para cada perfil de consumidor.

Devido à grande importância (ou necessidade) de se garantir a satisfação de seus diversos clientes, as instituições bancárias elaboram ações específicas voltadas para cada perfil de consumidor, buscando desenvolver comportamentos positivos em relação aos objetos tecnológicos. Desse modo, conhecer a opinião dos consumidores sobre o que desejam e o que valorizam se torna fundamental.

\section{ASPECTOS METODOLÓGICOS}

Esta pesquisa tem natureza qualitativa, pois nela o "pesquisador participa, compreende e interpreta" (MICHEL, 2015, p.42). E foi desenvolvida com o método de estudos de casos múltiplos já que esta metodologia permite a observação de evidências em diferentes contextos, pela replicação do fenômeno, sem necessariamente se considerar a lógica de amostragem (YIN, 2001).

O universo da pesquisa inclui os aplicativos mobile disponibilizado pelo Banco do Brasil e da Caixa Econômica Federal em agosto de 2017. Quando a pesquisa envolve um ou mais estudos de caso, Yin (2005) informa que é necessário que as informações sejam originárias a partir de três fontes diferentes de pesquisa. Dessa forma, a conclusão do estudo será mais convincente por utilizar diferentes fontes de evidência.

A primeira fonte de coleta foi a observação encoberta e não participativa, na qual a pesquisadora não teve contato com o ambiente de investigação, apenas observou as ações desenvolvidas e as empresas não sabem que estão sendo investigadas. A segunda fonte de coleta foi a observação participativa, e aqui, no caso, a pesquisadora instalou e utilizou os aplicativos atuando como usuária dos mesmos. E a terceira fonte foi a análise de conteúdo que é "uma técnica de levantamento de dados que utiliza textos, falas, informações já coletadas, de forma extensiva, ou seja, é uma análise feita $a$ posteriori à coleta" (MICHEL, 2015, p.70). As unidades de análise utilizadas para esta pesquisa foram as funcionalidades encontrada em cada caso.

\section{APLICATIVOS DO BANCO DO BRASIL E CAIXA: FUNCIONALIDADES E INTERATIVIDADE}

Tendo como base os construtos abordados no referencial teórico e a pesquisa exploratória realizada nos aplicativos do Banco do Brasil e Caixa, partimos para a análise descritiva dos objetos de estudo. 
APP BANCO DO BRASIL

O aplicativo do Banco do Brasil possui inúmeras funcionalidades, já na primeira tela o app mostra opções para abrir uma conta corrente e acessar a conta. A tela também mostra opções, como: BB Code; Financie; Emissão de senha; Ourocard-e; 2a via do boleto; Saque móvel; Apple Watch; Fale Conosco; Governo; Sua Empresa; Mais e Ligue pra nós. Além disso, a função "Abrir nova conta", possibilita abrir uma conta no BB, sem precisar fazer a solicitação através da agência física.

Bottentuit Junior (2008) aponta que a falta de tempo dos clientes também incentiva o uso desses serviços e de novos canais. Sendo assim, a ferramenta "Abrir nova conta", pode ser uma forma de capitalização de novos clientes para o Banco, já que elimina a burocracia tradicional para abrir uma conta corrente.

Para clientes BB é possível acessar a conta informando a Agência, Conta e Senha (8 dígitos). Existe o cadastro de senha provisória pelo APP, essa senha possibilita usar o autoatendimento BB pela internet e pelo celular e realizar consultas. Mas, para realizar transações financeiras e aquisição de produtos, a senha deve ser confirmada em um caixa eletrônico do Banco do Brasil. Se ativar a opção Touch ID, disponível somente para IOS (sistema operacional móvel da Apple Inc.), no próximo login será necessária autenticação biométrica. Isso vai de encontro a grande preocupação dos consumidores com a segurança ao usar aplicativos de banco, relatada na pesquisa Nielsen 2016. Apesar de não ser uma funcionalidade presente para todos os tipos de smartphones, indica uma preocupação da empresa e da criação de novas tecnologias para atender a necessidade do usuário.

Matos (2005) explica que a usabilidade é apenas uma parte dentro da aceitação do sistema, a sua aceitação total se dá através da combinação da sua aceitação social, a relação do sistema com práticas sociais vigentes, e da sua aceitação em categorias como o custo, a sustentação, a confiança, a compatibilidade com sistemas existentes, etc.

A usabilidade é dividida nas seguintes metas: ser eficaz no uso (eficácia); ser eficiente no uso (eficiência); ser segura no uso (segurança); ser de boa utilidade (utilidade); ser fácil de aprender (learnability); ser fácil de lembrar como se usa (memorability) (PREECE 2005). Ou seja, a confiança e a segurança no aplicativo são metas fundamentais para alcançar a usabilidade desejada.

Ao acessar a conta BB através do App, aparece a opção busca e de maneira fácil e rápida pode-se fazer qualquer transação. Existe um ícone (em forma de sino) para notificações, também um balão (de histórias em quadrinhos) para entrar em contato com o Banco e uma lupa para pesquisar o que deseja. Abaixo está o número da agência e da conta, ao lado um símbolo (feminino ou masculino), ao clicar você pode alterar foto do perfil, criar um apelido e acrescentar contatos. De acordo com os pesquisadores citados no artigo, Coyle e Thorson (2001) e Sohn e Lee (2005) e suas três características inerentes à internet: a terceira característica é a personalização.

Em seguida, o aplicativo mostra o saldo da conta corrente e lançamentos futuros. Extrato de conta; Transferências entre contas BB; Leitor de código de barras (você pode ler através da câmera do 
celular o código de barras do boleto); Solicitar empréstimo; Aplicação em fundos; Recarga de celular e Extrato fatura do cartão também estão disponíveis. Menu completo; Minha Página; Minhas Finanças e Ajustes são os últimos itens da tela.

No menu completo do aplicativo BB são disponibilizadas todas essas funções: acesso a Conta Corrente; Poupança; Pagamentos; Transferências; Cartões; Empréstimos; Soluções de Dívidas; Investimentos; Ponto pra Você; Débito Direto Autorizado; Câmbio; Viagens; Meus limites, Seguros, Ourocap, Brasilprev; Consórcios e Confirmações pendentes.

\section{APP CAIXA ECONÔMICA FEDERAL}

O aplicativo inicia com a frase A Caixa vai até você e abaixo expõe os símbolos de trevo de quatro folhas, celular, caixa aqui, navio, caixa eletrônico, computador e caminhão, ao clicá-los o usuário é direcionado para o site: caixa.gov.br.

Também existe no menu: Ajuda - Como acessar a conta; Contratos em atraso - Negociação de dívidas; Produtos - Loterias Caixa; Produtos/habitação - Simulador de habitação e, finalmente, Acessar minha conta (em destaque). Para acessar e obter todas essas informações é necessária identificação através do CPF.

Ao clicar em COMO ACESSAR A CONTA, o app direciona para uma tela que explica como ter acesso ao Internet Banking Caixa por meio de Tablet e Smarphone. Também direciona para o sistema compatível ao seu aparelho, podendo ser: APP STORE; GOOGLE PLAY; WINDOWS STORE. Ao clicar em Acessar minha conta abre-se a tela de identificação do usuário, o cliente deve se identificar como pessoa física ou jurídica e uma propaganda sobre o Internet Banking se faz presente. Para acessar a conta é necessário cadastrar senha e usuário da internet. E, para fazer transações financeiras, é preciso cadastrar uma assinatura eletrônica em qualquer terminal de autoatendimento Caixa.

O menu conta no aplicativo possibilita consultar Minha conta (saldo, extrato, cartão débito, transações, talão de cheques); Minhas Transferências; Investimentos; Poupança; Cartões; Serviço Cidadão; Pagamentos; Empréstimos e Loterias. Oferece também Promoções (descrição das promoções) e Para você (emissão da $2^{\mathrm{a}}$ via de boletos, descrição de serviços como seguros, capitalização, consórcios, previdência, imóveis à venda). No caso de ser uma conta empresarial, o aplicativo permite fazer uso de Contas; Investimentos; Cartões; Crédito e Financiamento; Imóveis; Serviços para o Judiciário; Crédito Rural; Conectividade Social e consulta de FGTS.

\section{COMPARAÇÃO ENTRE OS APLICATIVOS}

O aplicativo da Caixa possui várias funcionalidades como o aplicativo do BB. Porém, o app não é tão fácil de usar como o do seu concorrente, existem vários ícones que direcionam para a mesma 
função e pode deixar o utilizador confuso. Outra questão importante, o aplicativo pode se desconectar no meio de uma transação do usuário, fazendo com que este repita a função várias vezes. De acordo com Matos (2005), entende-se como propriedades das tecnologias a capacidade, o desejo e o interesse dos utilizadores ao fazerem uso de determinada tecnologia, esta é valorizada a partir das necessidades reais que aborda e a lacuna que preenche. Sobre essa perspectiva, o aplicativo do Banco do Brasil pode ser mais usado pelos consumidores do que o aplicativo da Caixa Econômica Federal.

O App do BB possui melhores avaliações e comentários dos seus usuários. Também é notável que os dois aplicativos passam por problemas, mas, como exposto na introdução deste trabalho, os aplicativos são atualizados de tempos em tempos para melhorar seu desempenho. Além disso, também é visível uma maior preocupação por parte do Banco do Brasil em resolver as falhas do aplicativo e tentar ajudar o usuário com o problema exposto.

Desse modo, como não é o intuito da pesquisa aprofundar-se nas avaliações dos aplicativos e considerando que o número de usuários do App da Caixa é maior que o número de usuários do App do BB (conforme dados da pesquisa Conectai presente na introdução do artigo), fica difícil afirmar a preferência dos usuários em relação aos dois aplicativos descritos ou ainda apontar qual deles é melhor ou pior. Apenas, essas avaliações fazem parte da descrição proposta no trabalho e das observações feitas através da pesquisa exploratória, mas sem dados suficientes para afirmações nesse sentido.

O quadro 02 apresenta um comparativo com as funcionalidades presentes nos dois App's BB e Caixa.

Quadro 02 - QUADRO COMPARATIVO DOS APLICATIVOS BB E CAIXA.

\begin{tabular}{|c|c|c|}
\hline FUNCIONALIDADE & BANCO DO BRASIL & CAIXA FEDERAL \\
\hline Abrir conta & $\mathrm{X}$ & \\
\hline Acessar conta & $\mathrm{X}$ & $\mathrm{X}$ \\
\hline BB Code & $\mathrm{X}$ & \\
\hline Financie & $\mathrm{X}$ & $\mathrm{X}$ \\
\hline Ourocard - e & $\mathrm{X}$ & \\
\hline 2 via do boleto & $\mathrm{X}$ & $\mathrm{X}$ \\
\hline Saque móvel & $\mathrm{X}$ & \\
\hline Apple Watch & $\mathrm{X}$ & \\
\hline Fale conosco & $\mathrm{X}$ & $\mathrm{X}$ \\
\hline Governo & $\mathrm{X}$ & \\
\hline Sua empresa & $\mathrm{X}$ & \\
\hline Mais & $\mathrm{X}$ & $\mathrm{X}$ \\
\hline Ligue para nós & $\mathrm{X}$ & $\mathrm{X}$ \\
\hline Leitor código de barras & $\mathrm{X}$ & $\mathrm{X}$ \\
\hline Crédito novo/empréstimos & $\mathrm{X}$ & $\mathrm{X}$ \\
\hline Aplicação de fundos & $\mathrm{X}$ & $\mathrm{X}$ \\
\hline Recarga de Celular & $\mathrm{X}$ & $\mathrm{X}$ \\
\hline Extrato da fatura do cartão & $\mathrm{X}$ & $\mathrm{X}$ \\
\hline Poupança & $\mathrm{X}$ & $\mathrm{X}$ \\
\hline Cartões & $\mathrm{X}$ & $\mathrm{X}$ \\
\hline
\end{tabular}




\begin{tabular}{|c|c|c|}
\hline Pagamentos & $\mathrm{X}$ & $\mathrm{X}$ \\
\hline Loterias & & $\mathrm{X}$ \\
\hline Serviço cidadão & & $\mathrm{X}$ \\
\hline Previdência & & $\mathrm{X}$ \\
\hline Habitação & $\mathrm{X}$ \\
\hline Capitalização & $\mathrm{X}$ \\
\hline Seguros & $\mathrm{X}$ & $\mathrm{X}$ \\
\hline Mensagem celular & $\mathrm{X}$ & $\mathrm{X}$ \\
\hline Extrato de conta & $\mathrm{X}$ & $\mathrm{X}$ \\
\hline Transferência & & $\mathrm{X}$ \\
\hline
\end{tabular}

Fonte: Dados da pesquisa

Os aplicativos Banco do Brasil e da Caixa Econômica Federal possuem funcionalidades (boa parte delas) semelhantes. Além do mais, as funcionalidades específicas existem nos dois aplicativos, como: Loterias, Serviço Cidadão e Previdência presentes no App da Caixa. E, do mesmo modo, o app do BB apresenta o serviço Abrir nova conta, BB Code, Apple Watch, Saque Móvel, entre outros.

$\mathrm{Na}$ questão usabilidade, facilidade ao usar a tecnologia e novas ferramentas, o aplicativo do Banco do Brasil está mais à frente que o aplicativo da Caixa Econômica Federal, este fato pode ser percebido através das descrições feitas, isto leva a vislumbrar uma melhor interação entre os usuários do aplicativo do BB em relação ao aplicativo da Caixa. Entretanto, ambos ainda vão sofrer muitas modificações, pois a tecnologia avança cada vez mais trazendo novas atualizações.

Vale lembrar que Matos (2005) aponta que as tecnologias digitais e novos media são encarados como uma expansão e um alargamento das experiências sensoriais e cognitivas do utilizador, nas quais se deve focar menos nas especificidades e características técnicas, e prestar especial atenção aos tipos e formas de uso por parte dos utilizadores. O sucesso de uma nova tecnologia é determinado através da sua apresentação e facilidade de uso e não pelo aparato tecnológico da ferramenta. Ou seja, o aplicativo precisa funcionar de forma adequada, deve ser fácil para o usuário e cumprir com aquilo que propõe a fazer, caso contrário, de nada vale a ferramenta.

\section{CONSIDERAÇÕES FINAIS}

Ao observar e descrever os aplicativos do Banco do Brasil e da Caixa Econômica Federal, destacam-se as funcionalidades presentes em ambos os aplicativos, como: acesso a conta, transferências e pagamentos. Essas são funcionalidades que ampliam a interação cliente e agência, pois ajudam os clientes a realizarem tarefas do cotidiano sem precisar ir até a agência bancária.

Funcionalidades específicas, como: consultar loterias, previdência e habitação presentes no app da Caixa também são importantes para os clientes que necessitam dessas informações. $\mathrm{O}$ app do BB se destaca por proporcionar novas funções, como: abrir nova conta, Apple watch ou saque móvel, essas ferramentas acrescentam ainda mais na interação consumidor e agência. Segundo Sicília, Ruiz 
e Munuera (2005), essas interações representam a facilidade com que indivíduos e organizações se comunicam diretamente uns com os outros sem restrições de distância ou tempo.

As interações entre banco e cliente através dos aplicativos ocorrem quando o aplicativo possui um design de interface de fácil compreensão, além da facilidade para o uso e funcionalidades adequadas. A principal diferença entre os dois App’s é que o aplicativo do BB está mais midiatizado em relação ao aplicativo da Caixa. O app do Banco do Brasil é mais organizado e moderno e esse fato parece deixar os consumidores do Banco do Brasil mais satisfeitos que os clientes da Caixa. O mobile banking do BB interage melhor com os seus clientes, promovendo uma relação que busca distanciar o espaço-tempo enquanto ajuda a reorganizar as tarefas diárias dos seus utilizadores.

\section{REFERÊNCIAS}

ABBADE, E.B.; NORO, G.B. Conhecimento, segurança, resistência e utilização de tecnologias de autoatendimento bancário. Revista de Administração da UFSM, v. 5, n. 3, p. 507-524, 2012.

BRADE, A. N., Shaping Web Usability: Interaction Design in Context, Addisson-westley, 2002.

BANCO DO BRASIL. Site do Banco do Brasil - BB Digital. Disponível em: https://bit.ly/2MPUcYM. Acesso em: 23 out. 2017.

BOTTENTUIT JUNIOR, J. B. Dispositivos e tecnologias móveis nas empresas: novas possibilidades para os negócios na era da informação. RNTI- Revista Negócios e Tecnologia da Informação, v. 3, n $1,2008$.

COYLE, J. R.; THORSON, E. The effects of progressive levels of interactivity and vividness in web marketing sites. Journal of Advertising, Memphis, v. 30, n.3, p. 65-78, Fall 2001.

CONECTAí Express. Pesquisa. Jun. 2017. Disponível em: https://bit.ly/37oRP8N. Acesso em: 18 jul. 2017.

DIX, A., Finlay, J., Abowd G. e Beale, R., Human-Computer Interaction, 3rd edition, Prentice Hall, 2004.

IAB Brasil - Março de 2013. Disponível em: https://bit.ly/3dVEaII. Acesso em Agosto de 2017. 
FEIJÓ, V. C.; GONÇALVEZ, B. S.; GOMEZ, L.S.R. Heurística para Avaliação de Usabilidade em

Interfaces de Aplicativos Smartphones: Utilidade, Produtividade e Imersão. Design \& Tecnologia 06. pgdesign. UFRGS, 2013.

FERNANDES, Maria Cecília. O que é um aplicativo móvel. Stone Blog. 11 ago. 2016. Disponível em: <http://blog.stone.com.br/aplicativo-movel/> Acesso em 18 jul. 2017.

KRETCH, D.; CRUTCHFIELD, R. S.; BALLACHEY, E. L. Individual in society: A textbook of social psychology. New York, NY: McGraw-Hill, 1962.

GROHMANN, M.Z. et al. Uma Análise sobre Intenção de Uso de Sistemas de Mobile Banking: Estudo pela Perspectiva do Custo x Benefício. In: XXXIX EnANPAD. Belo Horizonte - MG, 2015.

HJARVARD, S. Midiatização: conceituando a mudança social e cultural. Disponível em: https:// bit.ly/3hp7wRN. v. 8, n. 1, São Paulo, 2014.

IDGNOW. Quase 80\% dos internautas brasileiros usam aplicativos de bancos. Portal Terra. 17 jul. 2017. Disponível em: https://bit.ly/2UzSizK. Acesso em: 18 jul. 2017.

LAUDON, K. C.; LAUDON, J. P. Sistemas de Informação com Internet. Rio de Janeiro: LTC, 1999.

LING, Richard. The Mobile Connection, the Cell Phone's Impact on Society. Amsterdã: Elsevier/ Morgan Kaufmann, 2004.

MANI, Z.; CHOUK, I. Drivers of consumers' resistance to smart products. Journal of Marketing Management, v. 33, n. 1-2, p. 76-97, 2017.

MATOS, V. Dissertação: Usabilidade na Web e Usabilidade na Televisão Interactiva. Faculdade de Engenharia da Faculdade do Porto. Portugal. 2005.

MCMILLAN, S., Handbook of new media : social shaping and consequences of ICTs / ed. Leah A. Lievrouw, Sonia Livingstone, London, Sage Publications, 2002.

MICHEL, Maria Helena. Metodologia e pesquisa científica em ciências sociais: um guia prático para acompanhamento da disciplina e elaboração de trabalhos monográficos. 3. Ed. São Paulo: Atlas, 2015. 
NIELSEN.com. Pesquisa Nielsen sobre Pagamentos, Serviços Bancários e Compras via Celular. Março 2016. Disponível em: https://bit.ly/3hncNtq. Acesso em: 01 out. 2017.

PARASURAMAN COLBY, C. Marketing para produtos inovadores: como e por que seus clientes adotam tecnologia. São Paulo: Bookman, 2002.

PARASURAMAN COLBY, C. Tecno-ready marketing: how and why customers adopt technology. New York: The Free Press, 2001.

PEREIRA, V. A. Práticas de Comunicação e Linguagens Publicitárias nos Meios Digitais: Explorando o Projeto Transficção. In: XXIX Congresso Brasileiro de Ciências da Comunicação. Brasília, 2006.

PIRES, P. J.; COSTA FILHO, B. A. Fatores do índice de prontidão à tecnologia (TRI) como elementos diferenciadores entre usuários e não usuários de internet banking e como antecedentes do modelo de aceitação de tecnologia (TAM). Revista de Administração Contemporânea [online]. v. 12, n. 2, 2008.

PREECE, J.; ROGERS, Y. ; SHARP, H. Design de interação: além da interação homem- computador. Porto Alegre: Bookman, 2005.

ROBB, J.M., MCCARTHY, J. C.; SHERIDAN III, H. D. Intelligent interactivity. The Forrester Report, Cambridge, v. 1, n. 12, p. 10-18, 1997.

RAMOS, M. S. A, PIMENTA, L. I., RODRIGUES, B. A. P. Diferenças de Percepção de Adotantes e Não-Adotantes quanto ao uso de Serviços de Mobile Banking e sua Relação com as Características Individuais de Inovatividade. RPCA, v. 4, n. 3. Rio de Janeiro, 2010.

SCHIFFMAN, L. G.; KANUK, L. L. Comportamento do consumidor. 6. ed. Rio de Janeiro: LTC, 2000 .

SICILIA, M.; RUIZ, S.; MUNUERA, J. L. Effects of interactivity in a web site. Journal of Advertising, Memphis, v. 34, n. 3, p. 31-44, Fall 2005.

SOHN, D.; LEE B. Dimensions of interactivity: Differential effects of social and psychological factors. Journal of Computer-Mediated Communication, Bloomington, v. 10, n.3, Apr. 2005. Disponível em: https://bit.ly/3fjRMha. Acesso em 10 setembro 2017 
STRUTZEL, T. Presença Digital. Editora: ALTA BOOKS. Rio de Janeiro, 2015.

TERRA, Carolina. Blogs corporativos: Modismo ou tendência? São Caetano do Sul: Difusão Editora, 2008.

TURBAN, E. Electronic commerce: a managerial perspective. New Jersey: Pren ce-Hall, 2000.

YIN, R.K. Estudo de caso: planejamento e métodos. 3. ed. Porto Alegre: Bookman, 2005. 
